\title{
Sleep Deprivation Scale for Children and Adolescents
}

\section{Mehmet Kandemir $^{1} \oplus$, Edanur Bozdemir ${ }^{2} \oplus$, Yunus Hayran ${ }^{1} \oplus{ }^{\oplus}$ Zahide Tonga $^{1 \oplus}$, Aslı Kandemir ${ }^{3}$ [i]}

${ }^{1}$ Kırıkkale University, Faculty of Education, Department of Guidance and Psychological Counseling, Kırıkkale, Turkey

${ }^{2}$ Kırıkkale University, Social Sciences Institute, Department of Guidance and Psychological Counseling, Kirıkkale, Turkey ${ }^{3}$ Turkish Ministry of National Education, Kirikkale, Turkey

\begin{tabular}{|c|c|}
\hline ABSTRACT & ARTICLE INFO \\
\hline 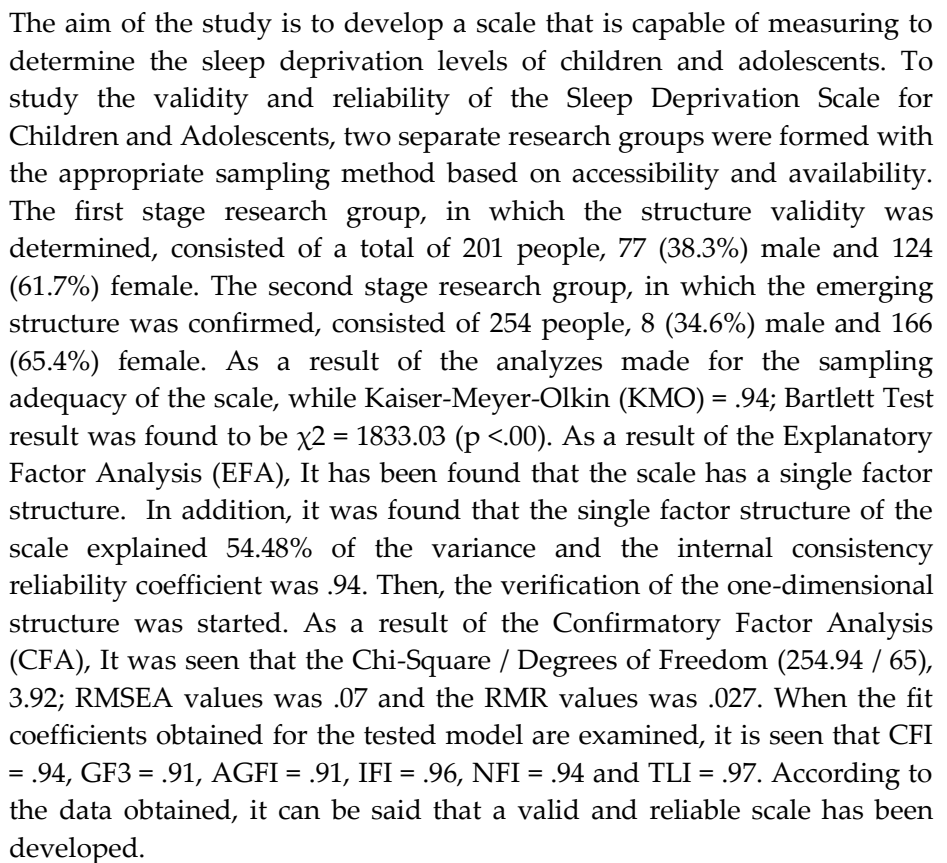 & $\begin{array}{l}\text { Article History: } \\
\text { Received: } 06.02 .2021 \\
\text { Received in revised form: } 07.03 .2021 \\
\text { Accepted: } 10.03 .2021 \\
\text { Available online: } 06.01 .2021 \\
\text { Article Type: Standard Paper } \\
\text { Keywords: Sleep, sleep deprivation, sleep } \\
\text { deprivation scale, child, adolescent }\end{array}$ \\
\hline
\end{tabular}

\section{Extended Summary}

\section{Introduction}

Sleep, which is defined as a life phase that can occur spontaneously, where the organism can reverse its interaction with the outside world with different stimuli, creates a temporary unconscious (Guytun, 1996). It is known that it is one of the important factors affecting the learning and developmental processes of children in school age (Walker, 2005). In childhood and adolescence, when learning and developmental processes are very fast, it is very valuable and important to determine whether sleep, which has a high effect on these processes, is sufficient for children and adolescents. Therefore, an examination of the increasing sleep deprivation experienced by children and adolescents during the day and to analyze which variables it is related to. It is possible to say that there are limited measurement tools to determine how the increasing sleep deprivation affects 
children and adolescents during the day. Accordingly, with this study, it was aimed to develop a valid and reliable scale for determining the sleep deprivation levels of children and adolescents.

\section{Method}

Two separate research groups were formed with the appropriate sampling method in order to carry out the validity and reliability study of the Sleep Deprivation Scale for Children and Adolescents. The first stage, where the construct validity was determined, consisted of a total of 201 people, 77 (38.3\%) male and $124(61.7 \%)$ female. The second stage research group, in which the structure was confirmed, consisted of 254 people, $8(34.6 \%)$ male and $166(65.4 \%)$ female. It is seen that the average age of the first group from the study groups is 12.37 , and the average age of the second group is 11.87 . Before the analysis, $\mathrm{Z}$ scores were examined in terms of extreme values. As a result of the examination, it was determined that there were 3 data that were seen to be out of the +3 and -3 values and they were removed from the data set. Then, Exploratory and Confirmatory Factor Analyzes were conducted on the data collected from the research group. One of the prerequisites of Exploratory Factor Analysis used to test construct validity in the scale development process is the absence of multiple and dual / uniqueness problems (Tabachnick \& Fidel, 2001). Correlation analysis was conducted to determine whether this problem existed. As a result of the test, it was determined that the correlation coefficients between items were between .15 and .69. According to the correlation analysis result, it was decided that there was no multi-linearity and singularity problem for the data set created for the validity and reliability analysis of the scale.

\section{Findings}

As a result of the analysis for the sampling adequacy of the scale, Kaiser-Meyer-Olkin (KMO) was found as .94; Bartlett Test result was found to be $\chi 2=1833.03(\mathrm{p}<.00)$. As a result of the Explanatory Factor Analysis (EFA), it has been found that the scale has a single factor structure. In addition, it was found that the single factor structure of the scale explained $54.48 \%$ of the variance and the internal consistency reliability coefficient was .94 . Then, the verification of the one-dimensional structure was started. As a result of the Confirmatory Factor Analysis (CFA), It was seen that the Chi-Square / Degrees of Freedom (254.94 / 65), 3.92; RMSEA values was .07 and the RMR values was .027. When the fit coefficients obtained for the tested model are examined, it is seen that CFI $=.94$, GF3 $=.91$, AGFI $=$ $.91, \mathrm{IFI}=.96, \mathrm{NFI}=.94$ and $\mathrm{TLI}=.97$.

\section{Discussion and Results}

The scale structure determined as a result of the research has been discussed by comparing it with different research results (Johns, 1991; Spilsbury, Drotar, Rosen \& Redlin, 2007) in the literature. In the sleep deprivation scale prepared by Spilsbury et al. (2007), it is seen that there are four different structures: sleep in school, wakefulness in school, sleep after school and sleep during school journey. It is seen that the scale items and scope prepared by Spilsbury et al. (2007) are quite similar to the scale items and scope prepared by us. In the study, the results of eigenvalue, slope trend graph, structure validity showed the one-dimension structure of the scale clearly different from the study of Spilsbury et al.

As a result of the Exploratory Factor Analysis, Cronbach's alpha internal consistency analysis, item total correlation analysis, Confirmatory Factor Analysis and other analyzes used in the development of the Sleep Deprivation Scale for Children and Adolescents, it is possible to say that the measurement efficiency and reliability of the scale are quite good. Consequently, it is possible to say that a scale has been developed that can be studied with many concepts and issues related to the hypothesis that it may be related to the sleep deprivation and quality of children and adolescents who continue their school life (success, problem solving, test and performance anxiety, fear, trauma, depression, self esteem, etc.), when the scope of the scale is considered in terms of its items and findings. It is considered important to determine the relationship between the Sleep Deprivation Scale for Children and Adolescents and the scales that determine sleep problems. 


\section{Çocuk ve Ergenler İçin Uyku Yoksunluğu Ölçeği}

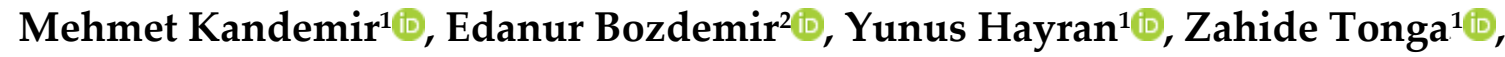 Aslı Kandemir ${ }^{3}$ [D}

${ }^{1}$ Kırıkkale Üniversitesi, Eğitim Fakültesi, Eğitim Bilimleri Bölümü, Rehberlik ve Psikolojik Danışmanlık ABD, Kırıkkale, Türkiye

${ }^{2}$ Kırıkkale Üniversitesi, Sosyal Bilimler Enstitüsü, Kırıkkale, Türkiye

${ }^{3}$ Turkish Ministry of National Education, Kirlkkale, Turkey

\begin{tabular}{|c|c|}
\hline Öz & MAKALE BİLGI \\
\hline 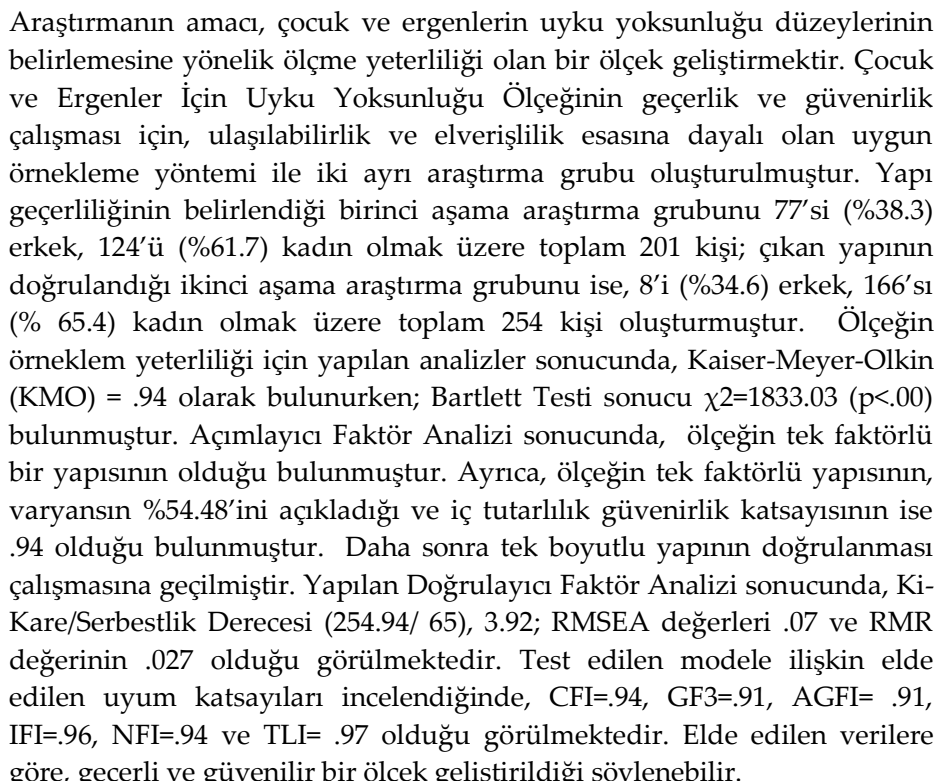 & $\begin{array}{l}\text { Makale Tarihçesi: } \\
\text { Alındı: 06.02.2021 } \\
\text { Düzeltilmiş hali alındı: } 07.03 .2021 \\
\text { Kabul edildi: } 10.03 .2021 \\
\text { Çevrimiçi yayınlandı: } 06.01 .2021 \\
\text { Makale Türü: Araştırma Makalesi } \\
\text { Anahtar Kelimeler: Uyku, uyku } \\
\text { yoksunluğu, uyku yoksunluğu ölçeği, } \\
\text { çocuk, ergen }\end{array}$ \\
\hline
\end{tabular}

\section{Giriş}

İnsanlar yaşamlarına devam edebilmek ve yaşam kalitelerini sürdürebilmek için temel ihtiyaçlarını gidermek zorundadırlar. Yeme-içme, güven, barınma gibi temel ihtiyaçların yanında, fizyolojik ve psikolojik sağlık açısından, uyku ve uyku sağlığının da insan organizması için önemli ve temel bir ihtiyaç olduğu söylenebilir. Uykunun temel bir ihtiyaç olduğunu ve bu ihtiyacın biyolojik ve psikolojik güçlenme için ön koşul olduğunu anlatan önemli araştırmacılar bulunmaktadır (Gerrig ve Zimbardo, 2012; Glasser, 1989; Maslow, 1943). Özellikle, Maslow (1943) uykuyu kendini gerçekleştirme hiyerarşisinde temel biyolojik ihtiyaçlar içinde değerlendirmiş ve diğer basamaklar için biyolojik ihtiyaçları ön koşul olarak belirtmiştir. Glasser (2989) ise, psikolojik sağlık için beş temel ihtiyaçtan birinin, uykuyu da kapsayan hayatta kalma ihtiyacı olduğunu belirterek uykunun önemini vurgulamıştır. İnsan doğası için oldukça önemli olan uyku; kendiliğinden ortaya çıkabilen, organizmanın dış dünya ile etkileşimini farklı uyarıcılarla geri döndürebilir olduğu, geçici bir bilinçsizlik hali oluşturan yaşam evresi olarak tanımlanmaktadır (Guyton, 1996). Çalıyurt (1998) ise uykuyu, organizmanın dinlenmesini sağlayan bir hareketsizlik olarak değil, bedenin aktif olarak kendini yenilemesini ve hayatını devam ettirebilmesi için gerekli enerjiyi sağlayan yaşam evresi olarak değerlendirmektedir.

Uyku, bütünsel bir görüntüsü olsa da, kendi içinde iki ana evreden oluşmaktadır (Guyton ve Hall, 2011). Uykunun birinci evresi REM evresi olarak tanımlanır ve bu evrede hızlı göz hareketleri ve kasların gevşemeye başlayarak uykuya geçilen evre olarak bilinmektedir. İkinci evre NONREM evresi

\footnotetext{
1 Sorumlu YazarAdres: Kırıkkale Üniversitesi, Eğitim Fakültesi, Eğitim Bilimleri Bölümü, Rehberlik ve Psikolojik Danışmanlık ABD, Kırıkkale, Türkiye e-posta: zahidetonga@gmail.com

DOI: https://doi.org/10.47157/jietp. 875187
} 
olarak tanımlanmaktadır (Owens ve Witmans, 2004). NONREM evresi, yavaş göz hareketlerinden oluşmaktadır. Bu evre toplam uyku süresinin neredeyse yüzde 75-80'lik kısmını oluşturur kendi içinde dört evreye ayrılmaktadır (İsmayılova, 2014). Birinci ve ikinci evreye yüzeysel yavaş uyku, üçüncü ve dördüncü evreye ise derin yavaş uyku adı verilmektedir. Birinci evreden dördüncü evreye doğru gidildikçe uyku derinleşir. Derin uyku uyunmadığında yorgunluk görülmektedir. İlk NONREM uykusu 70-100 dakika sürer ve bunun büyük bölümü evre 3-4'de geçer. Gece boyunca REM uykusunun süresi giderek azalır ve evre 3-4 kısalır. Sabaha karşı uyku ağırlıklı olarak REM ve evre 2 NONREM'den oluşur. Aynı şekilde yaş ilerledikçe 3. ve 4. evre kısalır. Üçüncü ve dördüncü evrede kişinin uyandırılması oldukça güçtür ve tam uyanıklık haline gelmesi 5 dakika alabilir. Normal sağlıklı bir bireyin gecelik uykusu boyunca bu fazlar 4-6 kez ardı sıra tekrar eder. Kişi uykuya ilk daldığında non-REM uykusunun ilk dört fazı geçilerek REM uykusuna başlanır (Guyton 1996). Gece uykusunu ortalama olarak, NONREM evreleri olan; \% 2-5'ini evre 1, \% 45-55'ini evre 2, \%2025'ini evre 3 oluşturmakla birlikte, \%20-25'ini de REM evrelerinin oluşturduğu bilinmektedir (Gerrig ve Zimbardo, 2012; Owens ve Witmans, 2004).

Uyku, sağlıklı bir yaşam tarzı sürdürmek için temel bir gereklilik olarak görülmekte ve insanların bu gereksinime doğuştan sahip oldukları belirtilmektedir (Gerrig ve Zimbardo, 2012). İnsan yaşamının üçte birlik bölümünü oluşturan uyku, doğumdan itibaren bireyin büyümesi ve gelişmesi için temel işlev görmesinin yanında; öğrenme, hafıza, bilgi işleme süreci, bilişsel gelişim, doku yenilenmesi, bağışıklık sisteminin güçlenmesi gibi birçok önemli işlevi yerine getirmektedir (Aydın ve Karaca, 1998; Campbell, Elder, Galland ve McDowall, 2017; Daşdemir, 2012; Guyton, 1996; Kaplan, Liu, Liu ve Owens, 2005; Lillis, Prisecilla ve Taylor, 2001; Oginska ve Pokorski, 2006). Uyku, bireylerin vücut sistemlerini çeşitli şekillerde etkileyebilen, düzenli bir şekilde gerçekleşen bir döngüdür. Her bireyin günlük karşılaması gereken bir uyku ihtiyacı vardır. Bu uyku süreleri/miktarları yaşlara göre değişmektedir (Daşdemir, 2012). Uyku süresine ilişkin çalışmalara bakıldığında; 6-13 yaşları arasında yer alan çocuklarda 9-11 saat; ergenlerde ise 8-10 saat arası uyku önerilmektedir (Albert, Alessi, Bruni, DonCarlos, Hirshkowitz ve Whiton, 2015). Bazı çalışmalarda okul dönemi çocukların günlük yaklaşık 9-10 saat uyku ihtiyacı olduğu ifade edilmektedir. (Farney, Jensen, Walker ve Walker, 1986; Güleç, 2003; Thiedke, 2001). Lee, Rankin ve Ward'a (2007) göre uyku, çocuk gelişiminin temel unsurudur. Buna bağlı olarak, her dört çocuktan birinde uyku sorunları görülmektedir (Meltzer ve Mindell, 2004). İlkokul çocuklarının \% 30'undan fazlası ve gençlerin \% 70'i uyku yoksunluğu yaşamaktadır (Keskin, 2016). Yaşanan bu uyku yoksunluğu sorunu; çocukların ve gençlerin hayatlarının birçok alanında önemli sonuçlar doğurmaktadır. Bülbül, Kurt, Ünlü ve Kırlı (2010) tarafından yapılan çalışmada daha kısa uyku bildiren çocuk ve ergenlerde, seçici dikkat ve karar verme mekanizmasının daha zayıf olduğu sonucuna ulaşılmıştır. Gruber, Raviv ve Sadeh (2002) yaptıkları çalışmada uykusuzluk nedeniyle bilişsel işlevlerin aksamasıyla beraber bellek ve bilgi işleme süreçlerinde bozulmaya neden olduğu ifade etmektedirler.

Çocuk ve ergenlerde ortaya çıkan uyku problemleri onların öğrenme süreçlerine olumsuz yansımakta ve bunun yanı sıra günlük yaşamdaki davranış örüntülerinde sorun/sorunlar olarak kendini göstermektedir (Aydın ve Yetkin, 2014; Kelman, 1999). Yeterli düzeyde uyku uyuyamayan, uyku yoksunluğu olan çocuk ve ergenlerde, uykunun ruh hali değişimlerine ve depresif hissetmeye neden olduğuna yönelik çalışmalar mevcuttur (Kelman, 1999). Uykunun en önemli işlevi, duygu düzenleme kapasitesini yeniden yapılandırmaktır (Dahl ve Lewin, 2002). Yeterli uyku miktarı karşılanmadığında düşük enerji, anksiyete, sinirlilik, duyguları kontrol etmede güçlük olduğu sonuçlarına ulaşılmaktadır. (Blum ve Carey, 1996; Dahl, 1996). Ergenlerle yapılan bir çalışmada, yetersiz uyku süresinin depresif ruh hali ve kendine zarar verme düşüncelerinin arttığına yönelik sonuçlar ifade edilmektedir. (Bautista, Foo, Shin ve YK, 2013). Fuligni ve Hardway (2006) tarafından yapılan bir diğer çalışmada ise; günlük tutan 14-15 yaş aralığındaki çocukların yazıları incelendiğinde; daha az uyuyan çocukların kendilerine ilişkin duygu durumlarını daha olumsuz betimledikleri vurgulanmaktadır. 
Uyku yoksunluğu, uyuyamama sorunundan farklı olarak, bireyin gün içerisinde karşılaması gereken uyku ihtiyacını içinde bulunduğu şartlardan dolayı veya isteyerek geciktirmesi sonucunda ortaya çıan uykudan yoksun kalma durumu olarak ifade edilmektedir. (Terman ve Terman, 2001). Uyku yoksunluğu çocukların fiziksel büyümesini, beyin gelişimini, bağışıklık sistemini etkilemektedir ve kilo alımında önemli bir rol oynadığı bilinmektedir. Uyku yoksunluğu, büyüme hormonlarında azalmaya neden olmaktadır (Akerstedt, Froberg ve Friberg, 1979; Akerstedt, Froberg ve Palmblad, 1979; Beck, 1981) bu da özellikle çocuklarda yavaş büyüme ve yavaş kilo alımı gibi sorunlara neden olabilir. Arlet, Jennifer, Kilkus ve Nedeltcheva (2009) tarafından yapılan araştırmalarda iştahı kontrol eden hormonların (leptin-ghrelin hormonları) uyku yoksunluğu nedeniyle değişebileceği sonucuna ulaşılmıştır. Çok az veya çok fazla uyku almak anormal kilo alımı ile ilişkilendirilebilir. Karaçal (2010) tarafından yapılan bir araştırmada, yeterli uyku almamak ve aşırı kilolu olmak arasında bir bağlantı olduğu sonucuna ulaşılmıştır. Bunun yanı sıra, Fredriksen, Reddy, Rhodes ve Way (2004) tarafından, kısa uyku süresi bildiren 6., 7. ve 8. sınıf öğrencileriyle yapılan boylamsal bir çalı̧̧mada, öğrencilerin özgüvenlerinde azalma saptanmıştır. Buna ek olarak literatürde, uyku yoksunluğu olan çocukların olumsuz beden algısına ve düşük benlik saygısına sahip olduğu (Deane, Fallone ve Owens, 2002; Owens, 2001sonucuna ulaşılan araştırmalar mevcuttur.

Uykunun, okul döneminde olan çocukların öğrenme süreçlerini etkileyen önemli göstergeleri olduğunu, uyku ile akademik süreçlerle ilgili ilişkilerin vurgulandığı önemli çalışmalar mevcuttur (Carskadon 2002; Carskadon ve Wolfson, 1998; Walker, 2005). Çalışmaların çoğunda uyku yoksunluğunun, yalnızca uykudan belirli bir süre önce öğrenilenler üzerinde değil, sonraki öğrenilecek olanlar üzerinde de olumsuz etki yaptığına ilişkin bulgular mevcuttur. Uykunun öğrenme öncesinde bilginin kodlanması ve öğrenilmiş bilginin kalıcı olmasında payı büyüktür (Walker, 2005). Carskadon ve Wolfson (1998) yaptıkları bir çalışmada, uyku süresi yeterli olan öğrencilerin, uyku yoksunluğu olan öğrencilere göre, zor olan derslerde daha başarılı olduğu, karmaşık matematik sorularını daha iyi çözdüğü, okuduğunu anlama becerilerinin ve öğrenme motivasyonlarının daha yüksek olduğu, daha yüksek notlar aldığını raporlamışlardır. Blum ve Carey (1996) ve Garrity (2007) tarafından yapılan çalışmalarda ise, öğrencilerin yaşadığı uyku yoksunluğunun dikkat ve motivasyon sorununa neden olduğu bulunmuş, çocuklarda uyku kaybının sözel yaratıcilığı ve soyut düşünme yeteneğini azalttı̆̆ belirtilmiştir. Bonnie, Findley ve Levinson (1992), uyku yoksunluğu gün içinde kaza ve yaralanma riskini arttırdığını belirterek, uyku sorunu yaşayan bireylerde dikkat ve koordinasyon sorunu vurgulamıştır.

Çocuk ve ergenlerin uyku süreçleri ile ilgili literatürde, hafta içi ve hafta sonu uyuma ve uyanma sürelerindeki farklılıklar, okulun erken saatlerde başlaması, sosyal aktiviteler, gün içerisinde teknolojiyle etkileşimlerinin fazla olması, artan ev ödevleri, azalan ebeveyn kontrolü çocuk ve ergenlerin uyku kalitesi ve yoksunluğu ile ilişkili olduğu belirtilmektedir (Carskadon 2002; Ward, Rankin ve Lee, 2007). Bunların yanı sıra, etkilenen uyku kalitesinin gün içerisinde uyku yoksunluğuna sebep olduğu ve bu durumun okul performansını etkileyebilecek kronik yorgunluğa neden olabildiğine ilişkin bulgulara ulaşan araştırmalar da mevcuttur (Carskadon ve Wolfson, 1998; Badia, Burduvali, Drake, Jefferson, Nickel ve Roth, 2003). Literatürde yer alan tüm bu araştırmalar ışığında, uykunun okul dönemindeki çocuk ve ergenlerin yaşamlarında ve öğrenme süreçlerindeki etkisinin oldukça önemli olduğu sonucuna ulaşılabilir.

Yukarıdaki açılamalar açısından düşünüldüğünde, çocuk ve ergenlerin uyku sağlığının, sadece biyolojik bir gelişim için değil; öğrenme, anlama, bellek, dikkat, başarı, sürdürebilir motivasyon gibi akademik gelişim açısından da oldukça önemli olduğu görülmektedir. Buna göre, çocuk ve ergenlerin uyku yaşantılarının araştırılması, farklı yaşam alanlarının etkilerinin belirlenmesi ve koruyucu çalışmalar açısından değerli olacağı düşünülmektedir. Alanyazın incelendiğinde, uyku ve uyku yoksunluğunu belirlemeye yönelik ölçek çalışmalarının olduğu görülmektedir (Önder, Masal, Demirhan, Horzum ve Beşoluk, 2016; İzci, Ardıç, Fırat, Şahin, Altınörs ve Karacan, 2008). İzci ve arkadaşları (2008) tarafından Türkçeye uyarlanan uyku ölçeğinin, yetişkinler üzerinde kullanılabilir olduğu görülmektedir. Meijer and Van Den Wittenboer (2004) tarafından geliştirilip, Önder ve 
arkadaşları (2016) tarafından Türkçeye uyarlanan ölçek maddelerinin, gün içinde artarak yaşanan uyku yoksunluğu ile ilgili olmadığı ve gece uykusuna geçememekle ilgili olduğu gözlenmiştir. Ergenlerde, gün içinde artan uyku yoksunluğunu belirlemek için Spilsbury ve arkadaşları (2007) tarafından hazırlanan uyku yoksunluğu ölçeğinin ise, sadece ergenlere yönelik olduğu ve çalışma grubunda ise uyku sorunu tanısı almış ergenlerin olduğu görülmüştür. Sonuç olarak, çocuk ve ergenlerin gün içindeki artan uyku yoksunluğunu ve bu yoksunluğun günlük yaşantıya yansımalarını belirlemek için ölçme yeteneği ve kararlılığı olan geçerli ve güvenilir bir ölçme aracına ihtiyaç olduğu düşünülmektedir.

\section{Yöntem}

\subsection{Araştırmanın Grubu}

Çocuk ve Ergenler İçin Uyku Yoksunluğu Ölçeğinin geçerlik ve güvenirlik çalışması için, ulaşılabilirlik ve elverişlilik esasına dayalı olan uygun örnekleme yöntemi (Berg, 2001) ile Açımlayıcı ve Doğrulayıcı Faktör Analizlerinde kullanılmak üzere iki ayrı araştırma grubu oluşturulmuştur. Birinci aşamada oluşturulan araştırma grubu, ölçeğin temel yapısını ve güvenirlik çalışmalarını yürütmek amacıyla oluşturulmuş; ikinci aşamada oluşturulan araştırma grubu, birinci aşamada çıkan yapının farklı bir veri setinde ne derece doğrulandığını Doğrulayıcı Faktör Analizi ile belirlemek amacıyla oluşturulmuştur. Birinci aşama için oluşturulan araştırma grubunda, 77'si (\%38.3) erkek, 124'ü (\%61.7) kadın olmak üzere toplam 201 kişi bulunmaktadır. Bryman ve Cramer'a (2001) göre, ölçek geliştirme sürecinde araştırma grubunun ölçek madde sayısının 5 ile 10 ile çarpımı kadar olması gerekmektedir. Kline (1994) ise benzer bir açılama ile örneklem büyüklügünün madde sayısının 10 katı olmasının yeterli olduğunu söylemektedir. Bu açıklamalara göre, bu araştırmada ulaşılan örneklem sayısının da yeterli olduğu değerlendirilmektedir. Araştırma grubundakilerin yaşları 8 ile 17 arasında değişmekte olup, yaşları ortalaması 12.37 olduğu görülmektedir. Aynı zamanda, araştırma grubundaki çocuk ve ergenlerden günlük uyku süreleri, uyuma saatleri ve uyuma saatlerine yönelik bazı istatistiksel veriler toplanmıştır. Buna göre, araştırma grubundaki bireylerin 15'inin (\%7.5) altı saatten az, 78'inin (\% 38.8) altı ile sekiz saat arası, 90'ının (\%44.8) sekiz ile on saat arası ve son olarak $18^{\prime}$ inin (\% 9) on saat ve üzeri günlük uyku sürelerinin olduğu; 11'inin (5.5) akşam 22.00'dan önce uyumaya başladığı̆, 84'ünün (\%41.8) 22.00 ile 00.00 arasında uyumaya başladığın ve 104'ünün (\%51.7) 00.00 'dan sonra uyumaya başladığ görülmektedir.

Ölçeğin geliştirilmesi sürecindeki ikinci aşama için oluşturulan araştırma grubunda, 88'i (\%34.6) erkek, 166'sı (\% 65.4) kadın olmak üzere toplam 254 kişi bulunmaktadır. Araştırma grubundakilerin yaşları 8 ile 17 arasında değişmekte olup, yaşları ortalaması 11.87 olduğu görülmektedir. Aynı zamanda, araştırma grubundaki çocuk ve ergenlerden günlük uyku süreleri, uyuma saatleri ve uyuma saatlerine yönelik bazı istatistiksel veriler toplanmıştır. Buna göre araştırma grubundaki bireylerin 12'sinin (\% 4.7) altı saatten az, 88'inin (\% 34.6) altı ile sekiz saat arası, 134'ünün (\% 52.8) sekiz ile on saat arası ve son olarak $20^{\prime}$ sinin (\% 7.9) on saat ve üzeri günlük uyku sürelerinin olduğu; 22'inin (8.7) akşam 22.00'dan önce uyumaya başladığı, 124'ünün (\% 48.8) 22.00 ile 00.00 arasında uyumaya başladığın ve 108 'inin (\%51.7) 00.00'dan sonra uyumaya başladığı belirlenmiştir.

\subsection{Veri Toplama Araçları}

Kişisel Bilgi Formu: Araştırma kapsamında, çocuk ve ergenlerin demografik açıdan değerlendirilmesi amacıyla araştırma kapsamında Kişisel Bilgi Formu oluşturulmuştur. Hazırlanan formda araştırma grubunun cinsiyet, yaş, uyku süreleri açısından değerlendirilmesi ile ilgili sorular bulunmaktadır.

Çocuk ve Ergenler İçin Uyku Yoksunluğu Ölçeği-Uzman Görüş Formu: Çocuk ve Ergenlerde Uyku Yoksunluğu Ölçeğinin geçerlik ve güvenirlik çalışması bağlamında, okula devam eden çocukların uyku gereksinimlerine ilişkin hazırlanan madde havuzunun uzmanlar açısından değerlendirilmesine ilişkin bu form oluşturulmuştur. Uzman Görüş Formunda uzmanlardan, oluşturulan maddelerin 
uygunluğuna ilişkin 0 ile 10 puan arasındaki derecelendirme puanları ve her bir maddeye ilişkin öneriler istenmektedir.

Çocuk ve Ergenler İçin Uyku Yoksunluğu Ölçeği-Uygulama Formu: Çocuk ve Ergenler İçin Uyku Yoksunluğu Ölçeğinin geçerlik ve güvenirlik çalışması içen hazırlanan madde havuzu ve uzman değerlendirmesi sonrasında uygulama için bu form oluşturulmuştur. Bu formla ilgili geçerlik ve güvenirlik sürecinin yanında psikometrik değerlendirme sonuçlarına, araştırmanın bulgular bölümünde verilmiştir.

\subsection{Veri Toplama Süreci ve Verilerin Analize Hazırlanması}

Araştırmada veri toplama süreci Covid-19 Pandemisinden dolayı online olarak gerçekleştirilmiştir. Google Form üzerinden toplanan veriler IBM SPSS'e girildikten sonra, verilerin analize hazırlanması işlemleri yapılmıştır. Bu bağlamda, verilerin z puanları uç değerler açısından incelenmiş +3 ile -3 değerleri dışında olduğu görülen 3 veri olduğu tespit edilmiş ve bunlar veri setinden çıkartılmıştır. Ölçek geliştirme sürecinde yapı geçerliliğini test etmek için kullanılan Açımlayıcı Faktör Analizinin ön koşullarından biri de çoklu ve ikili/teklik sorunun olmamasıdır (Tabachnick ve Fidel, 2001). Bu sorununun olup olmadığını belirlemek için korelasyon analizi yapılmış ve testin sonucunda maddeler arası ilişki katsayılarının 15 ile .69 arasında olduğu belirlenmiştir. Korelasyon analiz sonucuna göre, ölçeğin geçerlilik ve güvenirlik analizi için oluşturulan veri seti için çoklu doğrusallık ve tekillik sorununun olmadığına karar verilmiştir.

\section{Bulgular}

Çocuk ve Ergenler İçin Uyku Yoksunluğu Ölçeğinin geliştirilmesi sürecinde öncelikli olarak, uyku, uyku yoksunluğu, uyku kalitesi konularının kuramsal temelleri ilgili alanyazın araştırılarak elde edilen bilgiler incelenmiştir. İnceleme sonrasında, uyku yoksunluğu alanyazın kapsamında 20 maddelik "Çocuk ve Ergenler İçin Uyku Yoksunluğu Ölçeği Madde Havuzu" oluşturulmuştur. Aynı zamanda maddeler oluşturulurken, madde yazım kurallarına dikkat edilmiştir. Daha sonra, ölçek için oluşturulan madde havuzu, alanda uzman olarak çalışan 5 kişiye değerlendirmeleri için yönlendirilmiştir. Uzmanlardan gelen değerlendirmeler bağlamında, 3 madde ölçekten çıkartılmış, 2 maddede düzeltmeye gidilmiştir. Uzmanlardan gelen değerlendirmeler sonrasında Çocuk ve Ergenler İçin Uyku Yoksunluğu Ölçeğinin uygulama öncesindeki madde sayıları 17'ye inmiştir. Aynı zamanda, uzmanların ölçek maddelerine vermiş olduğu puanlar incelendiğinde, 7-10 puan arasında değişlik gösterdiği görülmüş ve puan ortalamaları 8.7 bulunmuştur. Bu işlemlerden sonra, 17 maddelik ve "kesinlikle katılmiyorum", "katılmıyorum", "katılıyorum" ve "kesinlikle katıliyorum" şeklinde hazırlanan 4'lü likert özelliği olan ölçeğin yapı geçerliliğini belirlemek için araştırma grubundan veri toplama sürecine geçilmiştir. Veri toplama süreci ve verilerin analize hazırlık süreci hakkında bilgiler araştırmanın yöntem bölümünde detaylı bir şekilde anlatılmıştır.

Çocuk ve Ergenler İçin Uyku Yoksunluğu Ölçeğinin uygulama formuyla toplanan ve ön koşul analizleri yapılan veriler üzerinde Açımlayıcı Faktör Analizi sürecine geçilmiştir. Açımlayıcı Faktör Analizi, faktörler ile göstergeleri arasında tanımlanan ilişkileri açıklayan ölçme modellerini test etmek için kullanılan çok değişkenli istatistik yöntemidir (Çokluk, Şekercioğlu, Büyüköztürk, 2012). Jöreskog ve Sörbom (1993) ise, gözlenen ölçümlerdeki, varyansın ve kovaryansın gizli kaynaklarını belirleyerek ölçeğin yapı geçerliliğini belirlemek için kullanılan bir yöntem olarak Açımlayıcı Faktör Analizini açıklamaktadır. Ölçeğin, geçerlik ve güvenirlik analizleri için birinci araştırma grubundan toplanan verilerin analizi sonrasında, Kaiser-Meyer-Olkin $(\mathrm{KMO})=.94$ olarak bulunurken; Bartlett Testi sonucu $\chi 2=1833.03 \quad(p<.00)$ bulunmuştur. Araştırmada KMO değerinin oldukça yüksek olduğu, Bartlett testinin anlamlı olduğu bulunmuş ve bu sonuçlara göre, araştırmanın örneklem büyüklüğünün mükemmel olması anlamına geldiği, literatür bilgisi bağlamında değerlendirilmiştir (Sharma, 1996). Ölçek maddelerinin faktör yük değerlerini belirlemek için kesme noktası olarak .40 belirlenmiştir. Büyüköztürk (2007), faktör yük değerinin sosyal bilimler için .30'un alt sinır olarak kabul edilebileceğini belirtmiş̧tir. Açıklayıcı Faktör Analizi sonucunda, ilk olarak maddelerin ortak 
faktördeki varyansı birlikte açılama düzeyleri incelenmiştir. Buna göre, 2 madde .40 'ın altında olduğu belirlenmiş ve bu 2 madde veri setinden çıkartılarak analizler tekrarlanmıștır. Bu işlemin arkasından yapılan analiz sonucunda, ölçeğin kaç faktörlü olabileceğine ilişkin öz değerler incelenmiş ve $1^{\prime}$ in üstünde tek faktörün olduğu bu inceleme sonrasında ortaya çıkmıştır. Öz değerlerin 1 ve üzerinde olması faktörün kararlığını göstermektedir (Çokluk, Şekerçioğlu, Büyüköztürk, 2012). Elde dilen tek faktörlü yapının öz değerinin 8.17 olduğu belirlenmiş ve dolayısıyla kararlılık gösteren tek bir faktörün olduğu değerlendirilmiştir. Tek faktörlü yapıyı görmek için aynı zamanda, Cattel'in yamaç eğim testi yapılmıştır. Kline'e (1994) göre bu test, en fazla anlamlı faktör sayısını belirgin hale getirmek amacıyla kullanılır. Yamaç eğilim analizi sonucunda, aşağıda verilen, Şekil 1'e ulaşılmıştır.

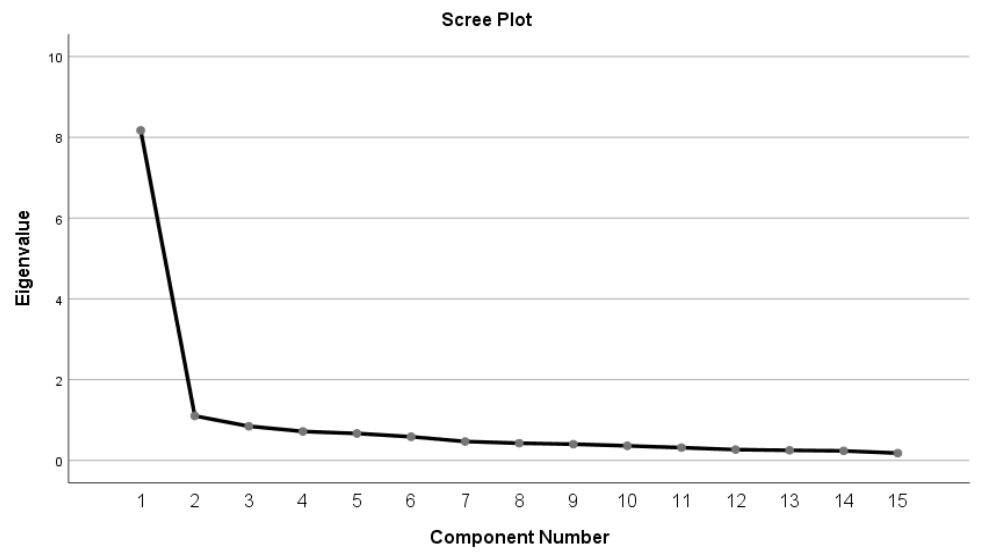

Şekil 1. Çocuk ve Ergenler İçin Uyku Yoksunluğu Ölçeği ile ilgili yamaç eğim grafiği

Şekil 1'deki grafiğe göre, ölçeğin tek kırılma noktasının olduğu görülmektedir. Tabachnick ve Fidel'e (2001) göre, değerlendirmelerde faktörler arasında keskinliği, belirginliği ve anlamlılığ sağlamak için döndürme (rotation) yapılması gerekmekte, dolayısıyla tek faktörlü bir yapıda bu işleme gerek duyulmamaktadır. Çocuk ve Ergenler İçin Uyku Yoksunluğu Ölçeğinin yapı geçerliliği çalışmasında tek faktörlü yapı açığa çıktığı için döndürme işlemlerine geçilmemiştir. Bu yüzden Çocuk ve Ergenler İçin Uyku Yoksunluğu Ölçeği tek boyutlu yapı olarak raporlanmıştır. Tek boyutlu yapıdaki her bir maddeyle ilgili yük değerleri, öz değerleri ve toplam varyans değerleri Tablo 1'de gösterilmiştir.

Tablo 1. Çocuk ve Ergenler İçin Uyku Yoksunluğu Ölçeği açımlayıcı faktör analizi sonuçları

\begin{tabular}{|c|c|c|c|}
\hline $\begin{array}{l}\text { Madde } \\
\text { No }\end{array}$ & Maddeler & $\begin{array}{l}\text { Faktör } \\
\text { Yükleri }\end{array}$ & $\begin{array}{c}\text { Ortak } \\
\text { Varyans } \\
\text { Değerleri }\end{array}$ \\
\hline 1 & Sabahları uyanırken güçlük çekerim. & .842 & .387 \\
\hline 2 & Daha fazla uyku uyuyabilmek için kahvaltı yapmadığım olur. & .815 & .411 \\
\hline 3 & Kahvaltı sırasında kendimi uykulu hissederim. & .808 & .542 \\
\hline 4 & Okula giderken kendimi uykulu hissederim. & .790 & .624 \\
\hline 5 & Dersleri dinlerken kendimi uykulu hissederim. & .782 & .664 \\
\hline 6 & Derslerde kendimi esnerken yakalarım. & .781 & .590 \\
\hline 7 & Ders sırasında zihnimi açık hissetmem. & .768 & .450 \\
\hline 8 & Teneffüslerde dışarı çıkmak yerine sınıfta uyurum. & .757 & .404 \\
\hline 9 & Okuldan eve gelir gelmez uyku ihtiyacı hissederim. & .737 & .474 \\
\hline 10 & Öğle yemeğinden sonra kendimi uykulu hissederim. & 689 & .470 \\
\hline 11 & Ödev yaparken uykum gelir. & .685 & .612 \\
\hline 12 & Gün içinde kendimi uyuşuk hissederim. & 671 & .610 \\
\hline 13 & $\begin{array}{l}\text { Yeteri kadar uykumu alamadığım için kendimi gün içinde yorgun } \\
\text { hissederim. }\end{array}$ & .641 & .653 \\
\hline 14 & Uykusuzluk nedeniyle günlük aktiviteleri unuttuğum olur. & 635 & .573 \\
\hline 15 & Uyku ile ilgili gün içinde şikâyetlerim olur. & 622 & .708 \\
\hline $\begin{array}{l}\text { Açıklan } \\
\text { Faktör Ċ }\end{array}$ & $\begin{array}{l}\text { Varyans Değer: } 54.48 \\
\text { Değerleri: } 8.17\end{array}$ & & \\
\hline
\end{tabular}


Tablo 1 incelendiğinde, Çocuk ve Ergenler İçin Uyku Yoksunluğu Ölçeğinin her bir maddelerine ilişkin faktör yük değerlerinin .622 ile .842 arasında değiştiği görülmektedir. Aynı zamanda, Çocuk ve Ergenler İçin Uyku Yoksunluğu Ölçeğinin tek faktörlü yapısının varyansın \%54.48'ini açıladığ1 ortaya çıkmıştır. Henson ve Roberts'a (2006) göre, açıklanan varyans oranının \% 50'nin üstü olması, ölçeğin ölçme düzeyinin yüksek olması anlamına gelmektedir. Scherer, Wieb, Luther ve Adams'a (1988) göre ise \%40 ile \%60 arasında değişim gösteren açılanan varyans düzeyleri oldukça yeterli bir düzeydir. Bu açıklamalara göre, Açımlayıcı Faktör Analizi sonucunda elde edilen varyans değerinin (\%54.48) oldukça iyi olduğu ve ortaya çıkan tek faktörlü yapının ölçme yeteneğinin yeterli olduğu ifade edilebilir.

Açımlayıcı Faktör Analizi sonrasında ortaya çıkan sonuçların, güvenilirliğini belirlemek amacıyla madde analiziyle yapılan, Cronbach alfa iç-tutarlılık değerleri incelenmiştir. Analiz sonrasında çıkan katsayı değerinin .94 olduğu belirlenmiştir. Özdamar (1999), .81 ile 100 arası güvenirlik katsayılarını yüksek düzeyde güvenirlik olarak tanımlamıştır. Buna göre, analiz sonrasında bulunan iç tutarlılık katsayısının oldukça yüksek bir değer olduğunu söylemek mümkündür. Aynı zamanda, güvenirlik çalışması yapılan “Çocuk ve Ergenler İçin Uyku Yoksunluğu Ölçeği"nde yer alan maddelerin, madde istatistiği olarak madde toplam korelâsyonu hesaplanmıştır. Bu analiz ile, her bir maddeden elde edilen uyku yoksunluğu puanı ile toplam uyku yoksunluğu puanı arasındaki ilişki anlamında kullanılmakta olup her bir uyku yoksunluğu maddesinin korelasyon katsayısı hesaplanmıştır. Analiz sonrasında çıkan sonuçlar Tablo 2' de verilmiştir.

Tablo 2. Çocuk ve Ergenler İçin Uyku Yoksunluğu Ölçek maddelerine ait istatistikler

\begin{tabular}{lcccc}
\hline & $\begin{array}{c}\text { Madde } \\
\text { ortalaması }\end{array}$ & $\begin{array}{c}\text { Madde standart } \\
\text { sapması }\end{array}$ & $\begin{array}{c}\text { Madde Toplam } \\
\text { Korelasyonu }\end{array}$ & $\begin{array}{c}\text { Madde Silme Güvenirlik } \\
\text { Katsayısı }\end{array}$ \\
\hline Madde 1 & 2.593 & 1.045 & .574 & .938 \\
Madde 2 & 1.954 & 1.078 & .593 & .938 \\
Madde 3 & 2.129 & 1.032 & .693 & .935 \\
Madde 4 & 2.293 & 1.101 & .750 & .934 \\
Madde 5 & 2.237 & 1.045 & .779 & .933 \\
Madde 6 & 2.299 & 1.034 & .722 & .934 \\
Madde 7 & 2.072 & .984 & .622 & .937 \\
Madde 8 & 1.541 & .858 & .585 & .938 \\
Madde 9 & 1.871 & .996 & .637 & .936 \\
Madde 10 & 1.732 & .965 & .636 & .936 \\
Madde 11 & 2.216 & 1.045 & .738 & .934 \\
Madde 12 & 1.948 & .953 & .735 & .934 \\
Madde 13 & 2.201 & 1.000 & .764 & .933 \\
Madde 14 & 1.855 & .970 & .710 & .935 \\
Madde 15 & 2.056 & 1.029 & .807 & .932 \\
\hline
\end{tabular}

Ölçeğin geliştirilmesi sürecindeki analizler sonrasında "Çocuk ve Ergenler İçin Uyku Yoksunluğu Ölçeği"nin çocuk ve ergenlerin uyku yoksunluğunu ölçme yeteneğine sahip olduğunu söylemek mümkün olsa da, ölçekten elde edilen yapının farklı bir veri setinde doğrulanması amacıyla, araştırmanın ikinci aşaması için toplanan verilerle Doğrulayıcı Faktör Analizi çalışması yapılmıştır.

Sümer'e (2000) göre, Doğrulayıcı Faktör Analizi ile boyutlar arasında oluşan ilişkiler, karşılaştırmalı hipotez modelleri test edilebilir ve modellerin iyilik derecesi belirlenmektedir. Doğrulayıcı Faktör Analiz çalışmaları, son zamanlarda ölçek geliştirme ve uyarlama temelli araştırmalarda yaygın bir şekilde kullanılmaktadır (Çapa, Çakıroğlu ve Sarıkaya, 2005). Açımlayıcı Faktör Analizi ile belirlenen tek boyutlu yapının 15 gözlenen değişkenden oluşan modelin analizi için Doğrulayıcı Faktör Analizine geçilmiştir. Buna göre, modelde ölçeğin temel yapısı Doğrulayıcı Faktör Analizine tabi tutularak uyum değerleri ortaya çıkmıştır. Elde edilen sonuçlara göre, KiKare/Serbestlik Derecesi (254.94/ 65), 3.92; RMSEA değerleri .07 ve RMR değerinin .027 olduğu görülmektedir. Test edilen modele ilişkin elde edilen uyum katsayıları incelendiğinde, CFI=.94, 
GF3=.91, AGFI $=.91, \mathrm{IFI}=.96, \mathrm{NFI}=.94$ ve TLI $=.97$ olduğu görülmektedir. CFI, GFI, IFI, NFI, TLI gibi uyum değerlerinin .90 ve .90 yakın olduğu görülmektedir. Ki-Kare değerinin 5 'ten, RMSEA ve RMR değerinin ise .08 'den küçük olması önerilen modelin uyum iyiliğinin yeterli olduğu anlamına gelmektedir (Şimşek, 2007). Doğrulayıcı Faktör Analizi sonucunda uyum iyiliği puanlarının yeterli olmasından dolayı iyileştirme indeksleri incelenmemiş olup, analiz sonucunda, madde ve tek fakötörlü yapı arasındaki ilişki değerlerine ait standardize edilmiş katsayılarla ilgili bulgular Şekil 1'te verilmiştir.

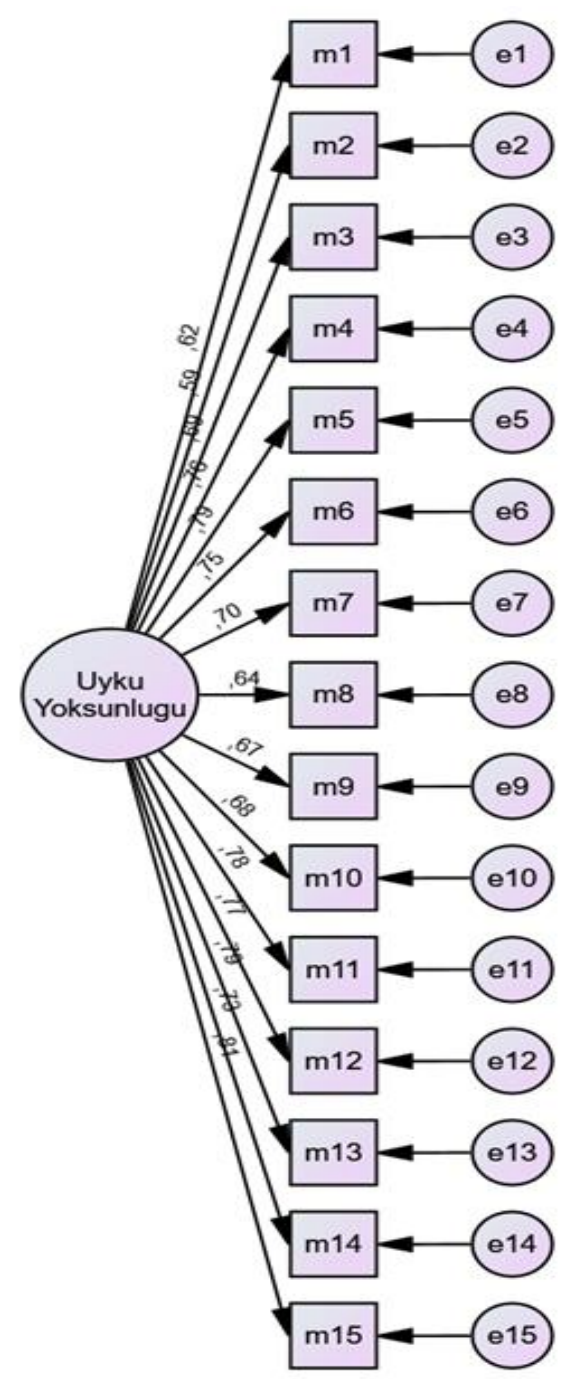

Şekil 2. Çocuk ve Ergenler İçin Uyku Yoksunluğu Ölçeğinin doğrulayıcı faktör analiz sonuç diyagram 1

Çocuk ve Ergenler İçin Uyku Yoksunluğu Ölçeğinin geliştirilmesi sürecinde kullanılan Açımlayıcı Faktör Analizi, Cronbach alfa iç-tutarlılık analizi, madde toplam korelasyon analizi, Doğrulayıcı Faktör Analizi ve diğer analizler sonucunda, ölçeğin ölçme yeterliliğinin ve güvenirliğinin oldukça iyi olduğunu söylemek mümkünüdür.

\section{Sonuç, Tartıșma ve Öneriler}

Çocuk ve ergenlerin gün içinde yaşadıkları uyku yoksunluğunu belirlemek amacıyla hazırlanan Çocuk ve Ergenler İçin Uyku Yoksunluğu Ölçeğinin geçerlilik ve güvenirlik çalışması sonucunda, tek boyutlu bir yapı ortaya çıkmıştır. Açımlayıcı faktör analizi sonrasında ortaya çıkan tek boyutlu yapı doğrulayıcı faktör analizi ve farklı güvenirlik hesaplamaları ile de doğrulanmıştır. Bulgular açısından düşünüldüğünde, ölçeğin ölçme yeteneğinin ve duyarlılı̆̆ının oldukça iyi olduğunu söylemek mümkündür. Alan yazın incelendiğinde, araştırmada açığa çıkan yapının desteklendiğini gösteren 
sınırlı düzeyde araştırmalar olduğunu söylemek mümkündür (Johns,1991; İzci ve diğ.,2008; Önder ve diğ., 2016). Fakat bu araştırmacıların hazırlamış ya da uyarlamış olduğu uyku kalitesi ile ilgili ölçekler gün içinde artarak yaşanan uyku yoksunluğu ve ihtiyacından çok, gece uykusuna geçememekle ilgili olduğu söylenebilir. Ergenlerde, gün içinde artan uyku yoksunluğunu belirlemek için Spilsbury ve arkadaşları (2007) tarafından hazırlanan uyku yoksunluğu ölçeğinde ise, okul içinde uyku, okul içinde uyanıklık, okul sonrası uyku ve okul yolculuğunda uyku olmak üzere dört farklı yapının olduğu görülmektedir. Spilsbury ve arkadaşlarının (2007) hazırlamış olduğu ölçek maddeleri ve kapsamı, tarafımızdan hazırlanan ölçek maddeleri ve kapsamı ile oldukça benzer olduğu görülmektedir. Araştırmada, öz değer, yamaç eğilim grafiği, yapı geçerlilik sonuçları ölçeğin tek boyutu yapısını Spilsbury ve arkadaşlarının çalışmasına göre, belirgin bir şekilde göstermiştir. Aynı zamanda, Spilsbury ve arkadaşlarının hazırlamış olduğu ölçeğin araştırma grubunu sadece 11 yaş ve üstü ergenler oluşturmuş olup, araştırma grubundaki ergenlerin 62'si uyku sorunu tanısını aldıkları raporlanmıştır. Hazırlanan bu ölçeğin geçerlilik güvenirlik çalışmasında örneklem olarak sadece ergenler değil, çocuklar da bulunmaktadır. Sonuçta, okul yaşamına devam eden çocuk ve ergenlerin uyku yoksunluğu ve kalitesi ile ilişkili olabileceği hipotezi ile ilgili pek çok kavram ve konuyla (başarı, problem çözme, sınav ve performans kaygısı, korku, travma, depresyon, benlik saygisı vb.) çalışılabilecek bir ölçeğin geliştirildiği, ölçeğin kapsamı, maddeleri ve bulgular bağlamında söylenmesi mümkündür.

Çocuk ve Ergenler İçin Uyku Yoksunluğu Ölçeğinin geçerlilik ve güvenirlik çalışması yapılırken bazı sinırlılıkların olduğunu belirtmek gerekir. Araştırma, Covid-19 Pandemisi döneminde yapılmıştır. Birey ve ailelerin bütün yaşam alanlarının etkilendiği ve değişim gösterdiği bu süreçte araştırma verileri toplanmıştır. Bazı öğrencelerin kısmen de olsa okul ve kurslara devam ettiği, uykuyla ilişkili döngülerin değiştiği, ekran karşısında normalden daha fazla kalmak zorunda olduğu, stres kaynaklarının değişim gösterdiği, belirsizliklerin artı̆̆ bir dönem olarak bu dönem açıklanabilir. $\mathrm{Bu}$ dönemde toplanan veriler ölçek yapısını ve sonuç değerlerini etkileyip etkilemediğinin pandemi sonrasındaki yeni araştırmalarda test edilmesi gerekmektedir. Çocuk ve Ergenler İçin Uyku Yoksunluğu Ölçeğinin, uyku sorunlarını belirleyen ölçeklerle de ilişkilerinin belirlenmesi, ölçeğin psikopatolojik anlamda uyku sorunlarını belirlerken yardımcı bir ölçek olmasına ya da çocuk ve ergenlere yapılacak müdahale programlarını etkililiğini görme açısından yardımcı bir araç olarak ölçeğin kullanılabileceği düşünülmektedir.

\section{Kaynakça}

Akerstedt, T. ,Froberg, J. E., \& Friberg, Y. (1979). Melatonin exceration, body temperature and subjective arousal during 64 hours of sleepdeprivation. Psyconeuroendocrinology, 4(3), 219-225.

Akerstedt, T., Froberg, J. \& Palmblad, J. (1979). Thyroid and adrenomedullary reactions during sleep deprivation. Acta Endocrinol, 90(2), 223-239.

Arlet, V. N., Jennifer, M. K., Jacqueline, I., Kristen, K., Dale, A. S., \& Plamen, D. P. (2009). Sleep curtailment is accompanied by increased intake of calories from snacks. The American Journal of Clinical Nutrition, 89(1), 126-33.

Aydın, H., \& Karacan, İ. (1998). Uyku ve psikofizyolojik süreçler. İçinde Güleç, C. \& Köroğlu, E. (Eds). Psikiyatri temel kitabı (ss. 673-80). Hekimler Yayın Birliği.

Aydın, H., \& Yetkin, S. (2014). Bir semptom ve bir hastalık olarak uykusuzluk. Journal of Turkish Sleep Medicine, 1(1), 1-8.

Badia, P., Burduvali, E., Drake, C., Jefferson, C., Nickel, C., \& Roth, T. (2003). The pediatric daytime sleepiness scale: sleep habits and school outcomes in middle-school children. Sleep, 26(4), 455-8.

Beck, U. (1981). Hormonal secretion during sleep in man. Modification of growth hormone and prolactin secretion by interruption and selective deprivation of sleep. International Journal of Neurology, 15(1-2), 17-29. 
Berg, B. L. (2001). Qualitative research methods for the social sciences (4th ed.). Nediham Heights: Allyn \& Bacon.

Blum, N. J., \& Carey, W. B. (1996). Sleep problems among infants and young children pediatrics in review. American Academy of Pediatrics, 17(3), 87-92.

Bonnie, R. J, Findley, L. J., \& Levinson, M. P. (1992). Driving performance and automobile accidents in patients with sleep apnea. Clinics in Chest Medicine, 13(3), 427-435.

Bryman, A., \& Cramer, D. (2001). Quantitative data analysis with SPSS release 10 for Windows. New York.

Bülbül, S., Kurt, G., Ünlü, E., \& Kırlı, E. (2010). Adolesanlarda uyku sorunları ve etkileyen faktörler. Çocuk Sağhı̆̆ı ve Hastalıkları Dergisi, 53(3), 204-210.

Büyüköztürk, Ş. (2007). Sosyal bilimler için veri analizi el kitabı. Pegem A Yayıncılık

Campbell, A. J., Elder, D. E., McDowall, P. S., \& Galland, B. C. (2017). Parent knowledge of children's sleep: A systematic review. Sleep Medicine Reviews, (31), 39-47.

Carskadon, M.A. (Eds). (2002). Adolescent sleep patterns: biological, social, and psychological influences. Cambridge University Press.

Carskadon, M. A., \& Wolfson, A. R. (1998). Sleep schedules and daytime functioning in adolescents. Child Development, 69(4), 875-887.

Çalıyurt, O. (1998). Sirkadiyen uyku uyanıklık düzenini etkileyen iş ve çalışma gruplarında uyku kalitesinin değerlendirilmesi (Uzmanlık tezi). Trakya Üniversitesi, Tıp Fakültesi, Psikiyatri Anabilim Dalı, Edirne.

Çapa, Y., Çakıroğlu, J., \& Sarıkaya, H. (2005). The development and validation of a Türkish version of teachers' sense of efficacy scale. Ĕgitim ve Bilim, 30 (137), 74-87

Çokluk, Ö., Şekercioğlu, G., \& Büyüköztürk, Ş. (2012). Sosyal bilimler için çok değişkenli istatistik SPSS ve LISREL uygulamaları. Pegem Akademi.

Dahl, R.E. (1996). The impact of inadequate sleep on children's daytime cognitive function. Seminars in Pediatric Neurology, 3(1), 44-50.

Dahl, R. E., \& Lewin, D. S. (2002). Pathways to adolescent health sleep regulation and behavior. J Adolesc Health, 31(6), 175-84.

Daşdemir, F. (2012). Yaşamın ilk üç yılında uyku sorunları ve etkili uyku ekolojisi etmenleri. (Yüksek lisans tezi). Ege Üniversitesi Sağlık Bilimleri Enstitüsü, İzmir.

Deane, J. Fallone, G., \& Owens, J. A. (2002). Sleepiness in children and adolescents: Clinical implications. Sleep Medicine Reviews, 6(4), 287-306.

Drake C., Nickel C., Burduvali E., Roth T., Jefferson C., \& Badia, P. (2003). The pediatric daytime sleepiness scale: Sleep habits and school outcomes in middle-school children. Sleep, 26(4), 455458.

Farney, R. J., Jensen, R. L., Walker, L. E. \& Walker, J. M. (1986). Ear oximetry to detect apnea differentiterapid eye movement(REM) and non-REM (NREM) sleep. Screening for the sleep apnea syndrome. Chest Journal, 89(4), 533-539.

Fredriksen, K., Reddy, R., Rhodes, J., \& Way, N. (2004). Sleepless in chicago: tracking the effects of adolescent sleep loss during the middle school years. Child Development, 75(1), 84-95.

Fuligni, A. J., \& Hardway, C. (2006). Dimensions of family connectedness among adolescents with mexican, chinese, and european backgrounds. Developmental Psychology, 42(6),1246-1258.

Garrity, K. (2007). Delaware school nurse association-your child's sleep. https://www.dsna.org. 
Gerrig, J. R., \& Zimbardo, G. P. (2012). Psychology and life, psikoloji ve yaşam psikolojiye giriş. (19. Baskı) içinde (ss.141-143). Psychology and life. (Çev. Sart, G.). Nobel Akademik Yayıncılık.

Giedke, H., \& Schwarzler, F. (2002) Therapeutic use of sleep deprivation in depression. Sleep Medicine Reviews, 6(5), 361-377.

Glasser, W. (1989). Reality therapy: A new approach to psychiatry. Harper \& Row Publisher.

Gruber, R., Raviv, A., \& Sadeh, A. (2002). Sleep neurobehavioral functioning and behavior problems in school age children. Child Development, 73(2), 405-417.

Güleç, G. (2003). http://uykubozuklugu.uludag.edu.tr/dersnotları001htm.

Guyton, A. (1996). Tibbi fizyoloji. (ss.761-765). Nobel Tip Kitapevi.

Guyton, A., \& Hall, (2011). States brain activity - sleep, brain waves, epilepsy, psychoses. in: Textbook of medical physiology in (pp. 721-28). WB Saunders.

Guyton, A., \& Hall, J. (1996). Tıbbi fizyoloji. (9.Baskı) içinde (ss.761-763). (Çev. Çavuşoğlu, H.). Nobel Tip Kitapevi.

Henson, R. K., \& Roberts, J. K. (2006). Use of exploratory factor analysis in published research. Educational and Psychological Measurement, 66(3), 393-416.

Hirshkowitz, M., Whiton, K., Albert, S. M., Alessi, C., Bruni, O., DonCarlos, L., Hazen, N., Herman, J., Adams Hillard, P. J., Katz, E. S., KheirandishGozal, L., Neubauer, D. N., O'Donnell, A. E., Ohayon, M., Peever, J., Rawding, R., Sachdeva, R. C., Setters, B., Vitiello, M. V., \& Ware, J. C. (2015). National sleep foundation's updated sleep duration recommendations: Final report. Sleep Health, 1(4), 233-43.

İzci, B., Ardıç, S., Fırat, H., Şahin, A., Altınörs, M., \& Karacan, I. (2008). Reliability and validity studies of the Turkish version of the epworth sleepiness scale. Sleep Breath, 12(2), 161-168.

Johns, M. (1991). A new method for measuring daytime sleepiness. the epworth sleepiness scale. Sleep, 14(6), 540-545.

Jöreskog, K. G., \& Sörbom, D. (1993). LISREL 8: Structural equation modeling with the SIMPLIS command language. Scientific Software International.

Kaplan, D. L., Liu, L., Liu, X., \& Owens, J. A. (2005). Sleep patterns and sleep problems among schoolhildren in the United States and China. Pediatrics. January, 115(1), 266-268.

Karaçal, Ş. (2010). Konya ilinde yaşayan 0-17 yaş grubu çocuklarda uyku bozukluklarının sıklığı (Uzmanlık tezi). Selçuk Üniversitesi, Meram Tıp Fakültesi, Çocuk Sağlığı ve Hastalıkları Anabilim Dalı, Konya.

Kelman, B. B. (1999). The sleep needs of adolescents. Journal of School Nursing, 15(3), 14-19.

Kline, P. (1994). An easy guide to factor analysis. Routledge.

Kyung Do, Y., Shin, E., Bautista, M.A., \& Foo, K. (2013). The associations between self-reported sleep duration and adolescent health outcomes: What is the role of time spent on Internet use? Sleep Medicine, 14(2), 195-200.

Lee, K. A., Rankin, S., \& Ward, T. M. (2007). Caring for children with sleep problems. Journal of Pediatric Nursing, 22(4), 283-296

Lillis, C., Prisecilla, L. M., \& Taylor, C. (2001). Fundamentals of the nursing in (pp.1013-36). JB Lippincott Company.

Maslow, A. H. (1943). A theory of human motivation. Psychological Review, 50(4), 370-396. 
Meltzer, L. J., \& Mindell, J. A. (2004). Nonpharmacologic treatments for pediatric sleeplessness. Pediatric Clinics of North America, 51(1), 135-151.

Meijer, A. M., \& Van Den Wittenboer, G. L. H. (2004). The joint contribution of sleep, intelligence and motivation to school performance. Personality and Individual Differences, 37(1), 95-106.

Oginska, H., \& Pokorski, J. (2006). Fatigue and mood correlates of sleep length in three age-social groups: school children, students, and employees. Chronobiology International the Journal of Biological and Medical Rhythm Research, 23(6), 1317-1328.

Owens, J. A., \& Witmans, M. (2004). Sleep problems. Current Problems in Pediatric and Adolescent Health Care, 34(4), 154-179.

Owens, J. A. (2001). The practice of pediatric sleep medicine: Results of a community survey. Pediatrics, 108(3),51.

Önder, İ., Masal, E., Demirhan, E., Horzum, M.B., \& Beşoluk, Ş. (2016). Psychometric properties of sleep quality scale and sleep variables questionnaire in Turkish student sample. International Journal of Psychology and Educational Studies, 3(3), 9-21.

Özdamar, K. (1999). Paket programlar ile istatistiksel veri analizi. Kaan Kitabevi.

Scherer, Robert F., Wiebe, F. A., Luther, D. C., \& Adams J. S. (1988). Dimensionality of coping: Factor stability using the ways of coping questionnaire. Psychological Reports, 62, 763-770.

Sharma, S. (1996). Applied multivariate techniques. John Wiley \& Sons.

Spilsbury, J. C., Drotar, D., Rosen, C. L., \& Redline, S. (2007). The cleveland adolescent sleepiness questionnaire: A new measure to assess excessive day-time sleepiness in adolescents. Journal of Clinical Sleep Medicine, 3(6), 603-612.

Sümer, N. (2000). Yapısal eşitlik modelleri: Temel kavramlar ve örnek uygulamalar. Türk Psikoloji Yazlları, 3(6), 49-74.

Şimşek, Ö. F. (2007). Yapısal eşitlik modellemesine giriş, temel ilkeler ve lisrel uygulamaları. Ekinoks Yayınları.

Tabachnick, B., \& Fidel, L. S. (2013). Using multivariate statistics (6. edition). Allyn \& Bacon Inc.

Terrnan, J. S., \& Terman, M. (2001). Light therapy. In: Dement W. C. Kryger, M. H, M. D. \& Roth, T. (Eds). Principles and Practice of Sleep Medicine. 1259-71.

Thiedke, C. C. (2001). Sleep disorders and sleep problems in childhood. American Family Physician, 63(2), 277-284.

Walker, M. P. (2005). A refined model of sleep and the time course of memory formation. The Behavioral and Brain Sciences, 28(1), 51-64.

Ward, T. M., Rankin, S., \& Lee, K. A. (2007). Caring for children with sleep problems. Journal of Pediatric Nursing, 22(4), 283-296.

Wolfson, A. R., \& Carskadon M. A. (1998). Sleep schedules and daytime functioning in adolescents. Child Development, 69(4), 875-887. 